Journal of Clinical Investigation

Vol. 41, No. 1, 1962

\title{
EVIDENCE FOR ACTIVE CHLORIDE REABSORPTION IN THE DISTAL RENAL TUBULE OF THE RAT *
}

\author{
By FLOYD C. RECTOR, JR., and JAMES R. CLAPP $\dagger$ with the technical assistance \\ oF MARTHA HUDDLESTON \\ (From the Department of Internal Medicine, The University of Texas Southwestern Medical \\ School, Dallas, Texas)
}

(Submitted for publication June 19, 1961 ; accepted August 22, 1961)

There is now considerable direct evidence that sodium is actively reabsorbed by most portions of the nephron (1-3). The reabsorption of chloride, on the other hand, is generally considered to be a passive process driven by the electromotive forces arising from active sodium transport (4).

The evidence for this hypothesis of passive chloride reabsorption in the proximal tubule is impressive. Giebisch and Windhager (5) found in the proximal tubule of Necturus kidney that the relationship between the ratio of the unidirectional chloride fluxes and the transtubular potential is compatible with passive diffusion plus a large component of exchange diffusion. The existence of this component of exchange diffusion suggests the presence of a carrier system for chloride and raises the possibility of active as well as passive chloride transport. However, Windhager and Giebisch (6) subsequently demonstrated in the proximal tubule of rat kidney that the short-circuit current is approximately equal to net sodium reabsorption, indicating that sodium reabsorption accounts for most, if not all, active ion transport in the proximal tubule. This is strong evidence that passive diffusion, rather than active transport, constitutes the predominant reabsorptive mechanism for chloride in the proximal tubule.

Conditions for chloride reabsorption, however, differ in the proximal and distal tubules. In the proximal tubule chloride concentration is usually equal to or greater than that of plasma (3), so that chloride is reabsorbed against very little or no con-

\footnotetext{
* Supported in part by a grant from the National Institutes of Health and in part by a grant from the Dallas Heart Association. This work has been presented in part before the meeting of the Southern Society for Clinical Research in New Orleans, January 20, 1961, and in part before the meeting of the Society for Clinical Research, Atlantic City, April 30, 1961.

† Work done as a Public Health Service trainee of The National Institutes of Health.
}

centration gradient. In the more distal portions of the nephron, however, chloride may be reabsorbed against considerable concentration gradients (3). If the reabsorption of chloride were entirely passive, the maximal concentration gradient that could be established across the tubular epithelium would be related to the transtubular potential difference according to the Nernst equation,

$$
\mathrm{E}_{\hat{\mathrm{T}}}=-61.5 \log \frac{[\mathrm{Cl}] \mathrm{P}}{[\mathrm{Cl}] \mathrm{T} . \mathrm{F}}
$$

where $E_{T}=$ distal transtublar potential difference, $[\mathrm{Cl}]_{\mathrm{P}}=$ plasma chloride concentration corrected for plasma solids and Donnan effect, and $[\mathrm{Cl}]_{\text {T.F. }}$. $=$ chloride concentration in distal tubular fluid.

To investigate the mechanism of chloride reabsorption in the distal tubule, the relationship between $\mathrm{E}_{\mathbf{T}}$ and the ratio $[\mathrm{Cl}]_{\mathbf{P}} /[\mathrm{Cl}]_{\text {T.F. }}$ has been studied under experimental conditions favorable for the development of maximal chloride concentration gradients. In preliminary studies it was found that during $\mathrm{Na}_{2} \mathrm{SO}_{4}$ diuresis, $[\mathrm{Cl}]_{\text {T.F. falls }}$ to very low levels (less than $1.0 \mathrm{mEq}$ per $\mathrm{L}$ ). Consequently, all studies were performed on normal and salt-depleted rats during the constant infusion of hypertonic $\mathrm{Na}_{2} \mathrm{SO}_{4}$.

\section{METHODS}

Studies were performed on two groups of male SpragueDawley rats weighing 250 to $350 \mathrm{~g}$. One group was maintained on normal rat pellet diet and tap water. The second group was salt-depleted by the administration of a single dose of chlorothiazide, $15 \mathrm{mg}$ per $\mathrm{kg}$ body weight, by gastric tube. These rats were then maintained for at least 5 days on a salt-free diet and distilled water before being used in an experiment.

The rats were anesthetized by an intraperitoneal injection of sodium pentobarbital, $40 \mathrm{mg}$ per $\mathrm{kg}$, and placed on a heated animal board. The left kidney was exposed through a wide abdominal incision and suspended on a small glass cup anchored to the animal board. The surface of the kidney was illuminated with a Knisely quartz 
rod (7) continuously perfused with mineral oil. An initial intravenous injection of 0.4 to $0.5 \mathrm{ml}$ of indigo carmine was given 5 to 10 minutes before the experiment (preliminary experiments showed that this quantity of indigo carmine did not affect $\mathrm{E}_{\mathrm{T}}$ and did not interfere with the determination of chloride in tubular fluid). This caused the distal tubules to appear blue in contrast to the colorless proximal tubules, markedly simplifying tubular identification. The urine coming from the left kidney was collected from the ureter through a small-bore polyethylene tube under mineral oil. Sodium sulfate, $0.5 \mathrm{M}$, was infused intravenously at a rate of 0.02 $\mathrm{ml}$ per minute for 30 minutes before the collections and continued at this rate throughout the experiment.

$E_{T}$ was measured with glass microelectrodes which were pulled from 1-mm Pyrex tubing with an instrument similar to that described by Alexander and Nastuk (8). The electrodes were filled with $3 \mathrm{M} \mathrm{KCl}$ by boiling under vacuum. The tips of the electrodes selected for use had a diameter of approximately $0.5 \mu$, resistance of 5 to 50 megohms, and tip potential less than $10 \mathrm{mv}$. The electrode was placed in a small Lucite chamber filled with $3 \mathrm{M}$ $\mathrm{KCl}$; electrical contact was established with a $\mathrm{Ag}-\mathrm{AgCl}$ electrode mounted in the Lucite chamber, which then connected to the input of a Cary vibrating-reed electrometer. The chamber was mounted on the head of a DeFonbrune micromanipulator. The reference electrode, consisting of a $\mathrm{KCl}$ bridge in contact with a $\mathrm{Ag}-\mathrm{AgCl}$ electrode, was inserted into the psoas muscle of the rat. The measuring electrode was placed in contact with saline on the surface of the kidney and the tip potential balanced out by applying a bucking potential of appropriate sign and magnitude by means of a potentiometer in the reference side of the electrical circuit. The electrode was then inserted into the tubule lumen along its longitudinal axis in order to minimize the possibility of recording intracellular potential differences. One minute was allowed to elapse after puncture for the potential reading to stabilize. No potential readings were accepted that did not remain stable for at least 4 to 5 minutes. In order to obviate the recording of intracellular potential differences the electrode was slowly withdrawn through a distance greater than the diameter of a tubular cell; only those instances in which the potential difference did not change were accepted.

After measuring $E_{T}$, samples of fluid were collected from distal tubules with Pyrex glass micropipets with tip diameters of 5 to $8 \mu$. Intratubular pressure was usually high enough, owing to rapid solute diuresis, to permit fluid to enter the pipet spontaneously, thereby obviating the necessity for suction. This served to eliminate the danger, inherent in any degree of suction, of collecting fluid either distal or proximal to the puncture site. The site of puncture was localized by injecting with latex, macerating with 50 per cent $\mathrm{HCl}$ for 2 hours, and dissecting free the tubular cast. The distal convoluted tubule was laid out in linear fashion and measured with a micrometer eyepiece. The puncture site was then expressed as a percentage of the total distal tubular length.

$[\mathrm{Cl}]_{\text {T.F. }}$ were determined by the method of Ramsay, Brown and Croghan (9) as modified by Windhager and
Giebisch (3). All samples containing $1.0 \mathrm{mEq}$ per $\mathrm{L}$ or more of chloride were titrated amperometrically with an accuracy of \pm 2 per cent. However, in those samples with concentrations less than $1.0 \mathrm{mEq}$ per $\mathrm{L}$, the initial potential reading obtained when the sample was transferred to the silver-wire electrode was used to calculate the chloride concentration. For the apparatus to function properly in this range it was necessary to prepare fresh $\mathrm{Ag}-\mathrm{AgCl}$ and $\mathrm{NaNO}_{3}$ electrodes once or twice daily. A standard curve was determined each day, using chloride standards ranging from 10 to $0.01 \mathrm{mEq}$ per L. In this range the potential reading was linearly related to the $\log$ of chloride concentration (Figure 1). To determine the possible effect of other ions on the potential, chloride standards were prepared in a solution containing 50 mmoles per $\mathrm{L} \mathrm{K}_{2} \mathrm{SO}_{4}$ and 50 mmoles per $\mathrm{L}$ $\mathrm{Na}_{2} \mathrm{SO}_{4}$. This solution was chosen so as to approximate distal tubular fluid composition during $\mathrm{Na}_{2} \mathrm{SO}_{4}$ diuresis. Standards prepared in this manner gave the same potential readings as those prepared with distilled water (Figure 1). To check further for possible interfering substances that might be present in tubular fluid, rat urine of known chloride concentration (determined with a Cotlove chloridometer) was diluted serially to approximately $0.01 \mathrm{mEq}$ per L. Determinations of urine chloride in concentrations ranging from 1.0 to $0.01 \mathrm{mEq}$ per $\mathrm{L}$ were accurate to \pm 10 per cent. Duplicate or triplicate determinations were done on all samples, and each determination was bracketed between standards to detect any change in the sensitivity of the apparatus. Plasma chlo-

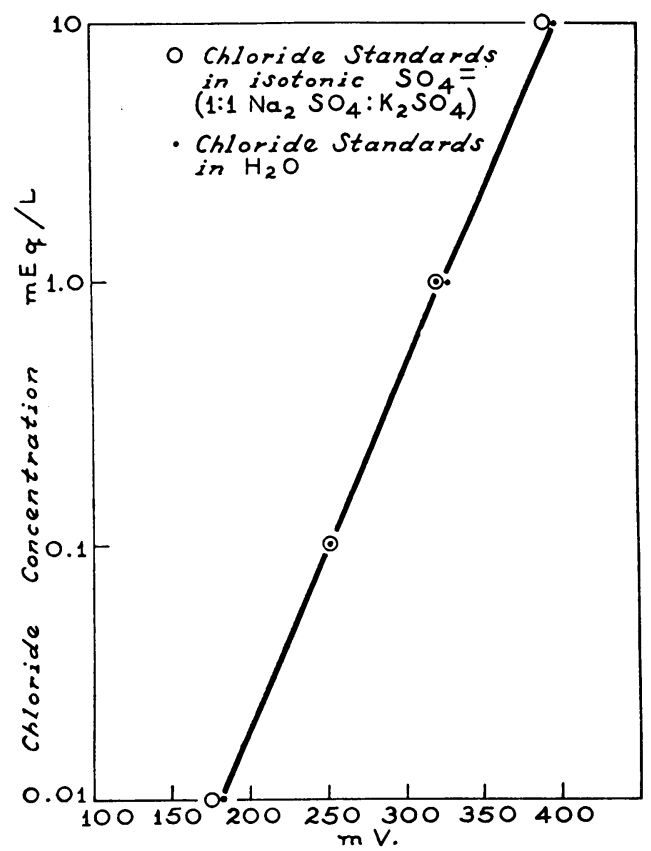

Fig. 1. Relationship between the concentration OF CHLORIDE IN STANDARD SOLUTIONS AND THE VOLTAGE READING OBTAINED WITH THE RAMSAY MICROCHLORIDOMETER. 
ride concentrations were measured with a Cotlove chloridometer.

\section{RESULTS}

Two types of experiments were undertaken. In one group of experiments $\mathrm{E}_{\mathrm{T}}$ and $[\mathrm{Cl}]_{\text {T.F. }}$. were measured in random distal tubules in 49 normal rats and 16 salt-depleted rats during $\mathrm{Na}_{2} \mathrm{SO}_{4}$ diuresis. In a second group of experiments in 11 normal and 4 salt-depleted rats determinations were made in the same distal tubule; $\mathrm{E}_{\mathbf{T}}$ was first measured, and fluid was then obtained for chloride analysis from the same puncture site.

As shown in Figure 2, $\mathrm{E}_{\mathbf{T}}$ in normal rats ranges from -30 to $-105 \mathrm{mv}$, with a mean of $-60 \mathrm{mv}$. The lumen in every instance was negative with respect to peritubular fluid. These values are similar to those obtained by Solomon (10). In salt-

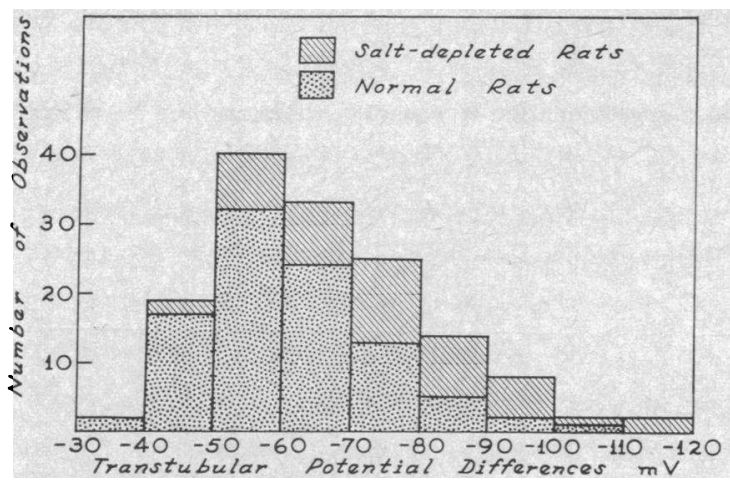

Fig. 2. Range of distal tRANSTUbular potential DIFFERENCES IN NORMAL AND SALT-DEPLETED RATS GIVEN $\mathrm{NA}_{2} \mathrm{SO}_{4}$

depleted rats $E_{T}$ was slightly higher, ranging from -40 to $-120 \mathrm{mv}$, with a mean of $-70 \mathrm{mv}$. The values represent measurements that were stable for at least 4 minutes and did not change when the electrode tip was withdrawn for a distance equal to the diameter of a single tubule cell. It is very unlikely, therefore, that any of these values represents intracellular potential differences. No correlation was observed between the site of the tubular puncture and the magniutde of $E_{T}$.

The range of all $[\mathrm{Cl}]_{\text {T.F. }}$ is illustrated in Figure 3. No differences were noted between normal and salt-depleted rats. The mean $[\mathrm{Cl}]_{\text {T.F. was }}$ $5.0 \mathrm{mEq}$ per L (range 24 to 0.013 ). Since the lower $[\mathrm{Cl}]_{\text {T.F. }}$ are the critical values in testing the hypothesis of passive reabsorption, it is important to note that, of approximately 260 measurements,

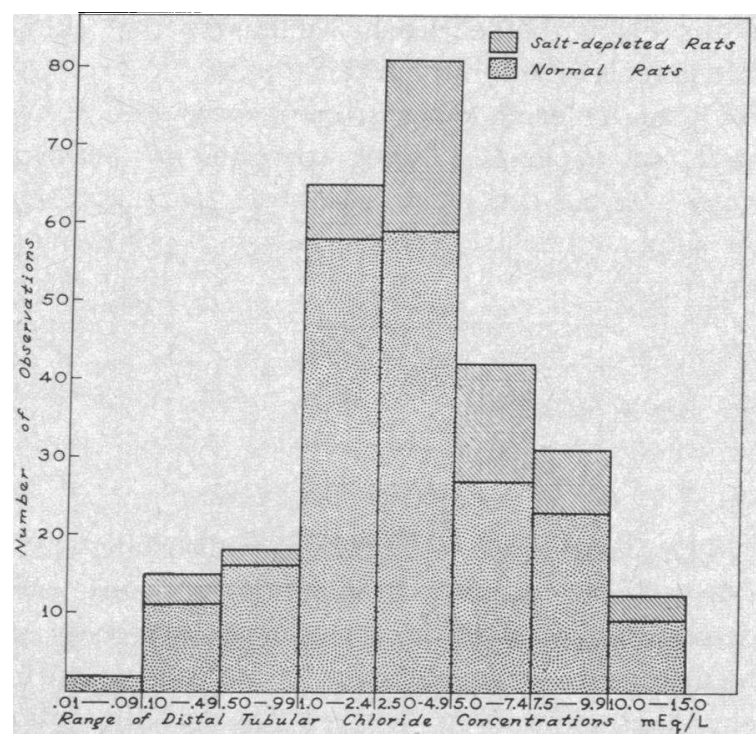

Fig. 3. RANGE OF distal tUBUlar CHLORIDE CONCENTRATIONS IN NORMAL SALT-DEPLETED RATS GIVEN $\mathrm{NA}_{2} \mathrm{SO}_{4}$.

36 (or 15 per cent) fell below $1.0 \mathrm{mEq}$ per $\mathrm{L}$. This relatively small number of observations below $1.0 \mathrm{mEq}$ per $\mathrm{L}$ reflects the percentage of samples. obtained from the terminal 15 to 20 per cent of the distal tubule.

The relationship between $[\mathrm{Cl}]_{\text {T.F. }}$ and site of puncture is shown more precisely in Figure 4. During $\mathrm{Na}_{2} \mathrm{SO}_{4}$ diuresis, fluid enters the distal tubule with chloride concentrations ranging from 4 to $14 \mathrm{mEq}$ per $\mathrm{L}$, and as the fluid traverses the

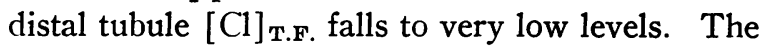
progressive fall in concentration along the length

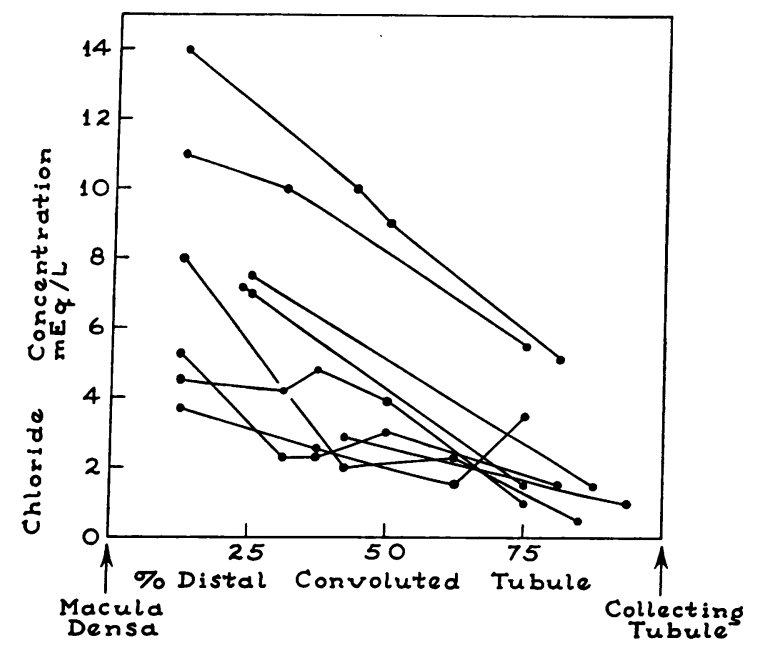

Fig. 4. Distribution of Chloride CONCENTRATIONS aloNg distal tUbule dURING $\mathrm{NA}_{2} \mathrm{SO}_{4}$ DiUREsis. 
of the distal tubule clearly establishes that chloride is reabsorbed in the distal tubule.

Plasma chloride concentrations were $89.0 \pm 2.0$ (SD) $\mathrm{mEq}$ per $\mathrm{L}$. When corrected for plasma water (93 per cent) and a Donnan factor of 1.05 , the estimated chloride concentration in peritubular water was $100 \pm 2.0 \mathrm{mEq}$ per $\mathrm{L}$. Ureteral urine chloride concentrations were $3.1 \pm 2.3 \mathrm{mEq}$ per $\mathrm{L}$ in the normal rats and $2.7 \pm 2.5 \mathrm{mEq}$ per $\mathrm{L}$ in the salt-depleted rats.

\section{DISCUSSION}

The distal tubule is capable of reabsorbing chloride against extreme concentration gradients. To determine whether this reabsorptive process is mediated by active transport or by passive diffusion the relationship between $E_{T}$ and the ratio, $[\mathrm{Cl}]_{\mathrm{P}} /[\mathrm{Cl}]_{\text {T.F. }}$, has been examined, utilizing the Nernst equation. Since this equation applies only to equilibrium states and since it is unlikely that equilibrium conditions ever exist across the tubular epithelium, the validity of its use in these studies may be questioned. Despite this objection, the Nernst equation can nevertheless be used to calculate the theoretical $[\mathrm{Cl}]_{\text {T.F. }}$ that would exist in electrochemical equilibrium with $[\mathrm{Cl}]_{\mathrm{P}}$ at any given $\mathrm{E}_{\mathrm{T}}$. This calculated $\mathrm{E}_{\mathrm{T}}$ represents the lowest possible concentration that could be achieved by passive diffusion along electrochemical gradients. If all the measured $[\mathrm{Cl}]_{\text {T.F. }}$ are above this limiting value, the only conclusion that can be drawn is that electrochemical equilibrium has not been attained and that the data are consistent with, but do not prove, passive diffusion. If, on the other hand, $[\mathrm{Cl}]_{\text {T.F. }}$ are obtained which are less than the limiting value defined by the Nernst equation, then active transport of chloride against an electrochemical gradient is clearly established.

In the present studies the highest measured $E_{\mathbf{T}}$ was $-120 \mathrm{mv}$ with the lumen negatively charged. An electromotive force of this magnitude could, in the face of a $[\mathrm{Cl}]_{\mathrm{P}}$ of $100 \mathrm{mEq}$ per $\mathrm{L}$, lower $[\mathrm{Cl}]_{\text {T.F. }}$ to $1.0 \mathrm{mEq}$ per $\mathrm{L},{ }^{1}$ but not below this

1 This can be readily established by substituting into the Nernst equation a value of $-120 \mathrm{mv}$ for $E_{\mathrm{T}}$ and 100 $\mathrm{mEq}$ per $\mathrm{L}$ for $[\mathrm{Cl}]_{\mathbf{P}}$ and solving for $[\mathrm{Cl}]_{\text {T.F. }}:-120=$ $-61 \log \left(100 /[\mathrm{Cl}]_{\text {T.F. }}\right)$, or $1.97=\log \left(100 /[\mathrm{Cl}]_{\text {T.F. }}\right)$. The antilog gives $94=100 /[\mathrm{Cl}]_{\text {T.F. }}$ Therefore, $[\mathrm{Cl}]_{\text {T.F. }}$. $=1.06 \mathrm{mEq}$ per $\mathrm{L}$.

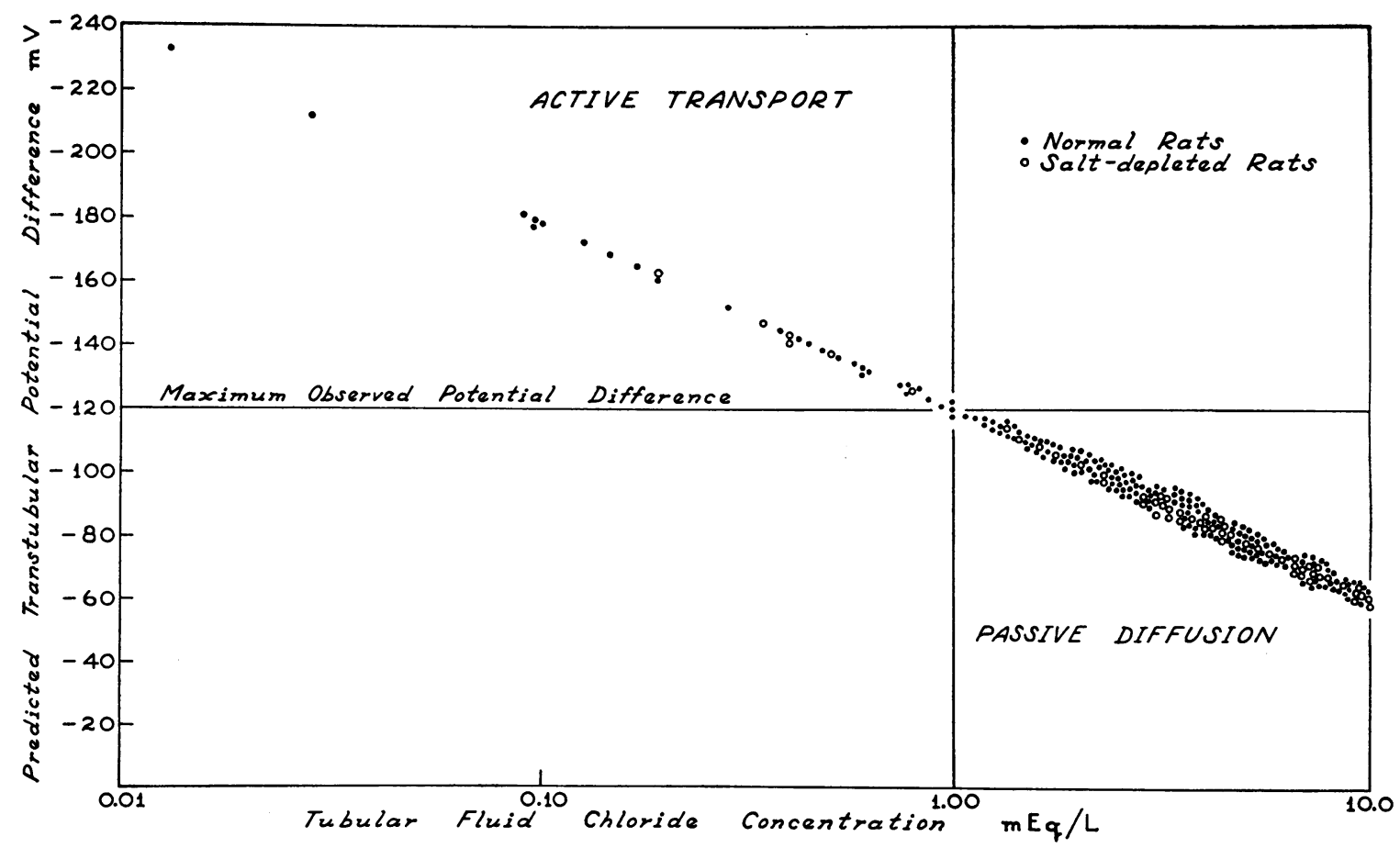

Fig. 5. RELATION OF CHLORIDE CONCENTRATION IN DISTAL TUBULE TO PREDICTED TRANSTUBULAR POTENTIAL DIFFERENCES estimated fRom the NeRnSt equation in RATS GIVEN $\mathrm{NA}_{2} \mathrm{SO}_{4}$. The horizontal line at -120 mv indicates the maximum observed potential difference (see text for discussion). 
value. Of 260 measurements, 36 (or 15 per cent) $[\mathrm{Cl}]_{\text {T.F. }}$ were below the critical value of $1.0 \mathrm{mEq}$ per L.

The relationship between distal $[\mathrm{Cl}]_{\text {T.F. }}$ and the maximal $\mathrm{E}_{\mathrm{T}}$ is illustrated in Figure 5 . The chloride concentrations are plotted along the horizontal axis. The predicted $\mathrm{E}_{\mathbf{T}}$ (calculated from the Nernst equation) required to produce the observed $[\mathrm{Cl}]_{\text {T.F. }}$ by a process of passive diffusion is plotted along the horizontal axis. The heavy horizontal line represents the highest observed $\mathrm{E}_{\mathrm{T}}$ of $-120 \mathrm{mv}$. Points falling below the line are compatible with passive reabsorption, while those points above the line represent $[\mathrm{Cl}]_{\text {T.F. }}$ that could not be produced by the highest $\mathrm{E}_{\mathrm{T}}$ observed. Some of the $[\mathrm{Cl}]_{\text {T.F. }}$. would, in fact, require $\mathrm{E}_{\mathrm{T}}$ as high as $-220 \mathrm{mv}$. Those points falling above the line, therefore, are incompatible with passive reabsorption and indicate an active transport of chloride.

The points falling below the horizontal line in Figure 5 and which, therefore, are compatible with passive reabsorption may be due to two factors. First, many of these samples were obtained from the first third of the distal tubule where the $[\mathrm{Cl}]_{\text {T.F. }}$ has not yet achieved its minimal value. Consequently, these points do not constitute a valid test of the reabsorptive mechanism. Second, although these $[\mathrm{Cl}]_{\text {T.F. }}$ are compatible with passive reabsorption when compared with the highest $\mathrm{E}_{\mathrm{T}}$, many of these values are incompatible with passive reabsorption when compared with the $E_{T}$ measured in the same tubule from which the sample was obtained.

Figure 6 represents the results of 51 determinations in which the $\mathrm{E}_{\mathrm{T}}$ was first measured, then a sample of fluid collected from the same puncture site for chloride analysis. The measured $\mathrm{E}_{\mathrm{T}}$ are plotted along the vertical axis and $[\mathrm{Cl}]_{\text {T.F. }}$ are plotted along the horizontal axis. The oblique line represents the $\mathrm{E}_{\mathrm{T}}$ necessary to produce the observed $[\mathrm{Cl}]_{\text {T.F. }}$ by passive reabsorption (calculated from the Nernst equation). All points falling on or above this line are consistent with passive reabsorption, while those falling below the line are not. Of 51 determinations only 3 fell on or above the line, indicating that the measured $\mathrm{E}_{\mathrm{T}}$ are insufficient to produce the observed $[\mathrm{Cl}]_{\text {T.F. }}$ by passive reabsorption. The data establish that $\mathrm{Cl}^{-}$ reabsorption in the distal tubule is mediated by an active process.

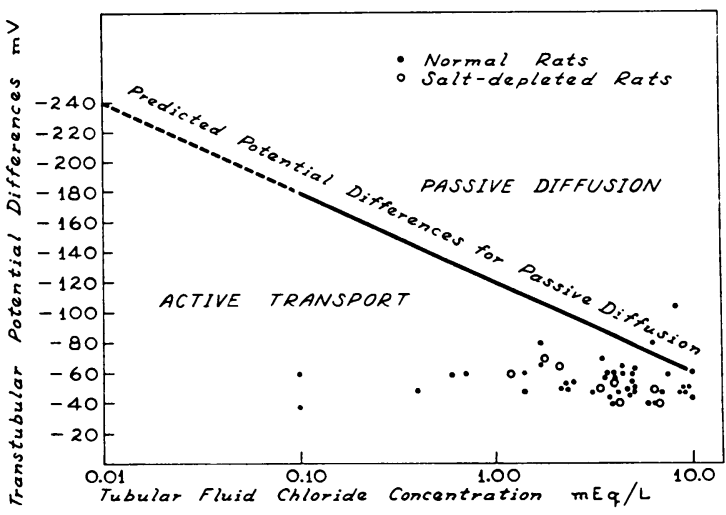

Fig. 6. Relation of transtubular potential DifFERENCE AND CHLORIDE CONCENTRATION FROM THE SAME Distal tUBULE. The heavy oblique line was calculated from the Nernst equation using the measured concentration of chloride in tubular fluid and $100 \mathrm{mEq}$ per L for chloride concentration in peritubular water. Points below the line indicate that the measured potential is too low to produce the observed distal tubular chloride concentration by a process of passive reabsorption (see text).

Three possible sources of error in these studies must be considered. First, there is the possibility of electrical shunting at the site of puncture, giving falsely low measurements for $E_{T}$. Recently Windhager and Giebisch (6) found in the proximal tubule of the rat that a locally applied current decreases progressively as it is propagated along the tubule, falling to 37 per cent of its original value at a point $55 \mu$ from the site of current application. In the present studies the tip of the measuring electrode was threaded along the longitudinal axis of the distal tubule for distances greater than 90 to $120 \mu$ ( 3 or 4 lumen diameters). Thus, if the electrical properties of the distal tubule are similar to the proximal tubule, any electrical shunting around the shaft of the electrode would only slightly alter the $\mathrm{E}_{\mathrm{T}}$ measured by the electrode tip 3 to 4 lumen diameters away. Further evidence against significant shunting is the fact that in most instances the electrode could be either inserted farther along the tubule or withdrawn for distances equal to 1 or 2 lumen diameters without changing $\mathrm{E}_{\mathrm{T}}$. In addition, the discrepancy between the measured $E_{T}$ and the $E_{T}$ necessary to produce the observed $[\mathrm{Cl}]_{\text {T.F. was, in some instances, as high }}$ as $120 \mathrm{mv}$. It is extremely unlikely that shunting of this magnitude would have occurred.

Second, there is the possibility that the measurements of $[\mathrm{Cl}]_{\text {T.F. }}$ were falsely low. Contami- 
nation of the sample of distal tubular fluid with proximal tubular fluid, interstitial fluid or plasma would all raise rather than lower the chloride concentration. It is unlikely that the low $[\mathrm{Cl}]_{\text {T.F. }}$. were due to analytical error, since each sample was measured in duplicate and carefully bracketed between standard chloride solutions. In addition, samples with chloride concentrations between 1 and $5 \mathrm{mEq}$ per $\mathrm{L}$ were determined from both the voltage obtained with the $\mathrm{Ag}-\mathrm{AgCl}$ electrode, as described in Methods, and by the amperometric titration as described by Ramsay and co-workers (9). The results obtained by the two different measurements always were within 5 per cent of each other. Moreover, it should be borne in mind that in many instances the measured $[\mathrm{Cl}]_{\text {T.F. }}$-in the range from 5 to $0.1 \mathrm{mEq}$ per $\mathrm{L}$-were 5 - to 100 -fold lower than those that could be achieved by the measured $\mathrm{E}_{\mathrm{T}}$ (Figure 6). Consequently, even if the measurement of $[\mathrm{Cl}]_{\text {T.F. }}$ were falsely low by 15 to 20 per cent, such an error could in no way account for the tremendous disparity between the measured $[\mathrm{Cl}]_{\text {T.F. }}$ and that which could result from passive diffusion along electrochemical gradients.

The third possible cause of error is that the actual concentration of chloride in peritubular water is much less than that estimated from the plasma concentration. This discrepancy might arise either because the distal tubule reabsorbate is hypotonic during osmotic diuresis or because the $\mathrm{HCO}_{3}{ }^{-}$to $\mathrm{Cl}^{-}$ratio is higher in the reabsorbate than in plasma, owing to the addition of $\mathrm{HCO}_{3}{ }^{-}$as $\mathrm{H}^{+}$is secreted. Both processes could result in a dilution of peritubular $\mathrm{Cl}^{-}$so that its concentration would be less than that estimated from plasma. The distal tubular fluid, however, is known to equilibrate to isotonicity (11), indicating that the peritubular fluid must also be isotonic. Thus, the hypotonicity of the reabsorbate cannot significantly alter peritubular chloride concentration. Since the relatively high blood flow in the cortex is capable of dissipating the effects of a hypotonic reabsorbate, it is similarly likely to counteract the effects of a high $\mathrm{HCO}_{3}{ }^{-}$to $\mathrm{Cl}$ ratio in the reabsorbate.

However, these considerations aside, even if the actual concentration of $\mathrm{Cl}^{-}$in peritubular fluid were significantly different from the concentration estimated from plasma, the disparity would have very little effect in the distal $\mathrm{E}_{\mathbf{T}}$ as calculated from the $\mathrm{Cl}^{-}$ratio. This becomes readily apparent from a consideration of the arithmetic of the Nernst equation. It should be emphasized that the numerator of the Nernst ratio, $[\mathrm{Cl}]_{\mathbf{P}}$, is so large with respect to the denominator that absolute changes of $[\mathrm{Cl}]_{\mathbf{P}}$ of considerable magnitude have comparatively minor effects on the ratio. $E_{T}$ is, therefore, relatively insensitive to changes in $[\mathrm{Cl}]_{\mathbf{P}}$. Consequently, even if the actual concentration of $\mathrm{Cl}^{-}$peritubular fluid were $75 \mathrm{mEq}$ per $\mathrm{L}$, instead of the estimated $100 \mathrm{mEq}$ per $\mathrm{L}$, this would lower the predicted $\mathrm{E}_{\mathrm{T}}$ necessary to produce the observed $[\mathrm{Cl}]_{\text {T.F. }}$ by only $7 \mathrm{mv}$. An error of this magnitude would not account for the discrepancies between the observed and predicted $E_{\mathbf{T}}$.

Thus, the results in the present study cannot be explained on the basis of underestimation of transtubular $E_{T}$ due to electrical shunting, underestimation of $[\mathrm{Cl}]_{\text {T.F. }}$ due to analytical errors, or overestimation of the $[\mathrm{Cl}]_{\mathbf{P}}$; and, therefore, they clearly indicate that in the distal tubule, chloride is actively reabsorbed against electrochemical gradients.

\section{SUMMARY}

The mechanism of $\mathrm{Cl}^{-}$reabsorption in the distal tubule was examined by determining the relationship between the distal transtubular potential difference $\left(\mathrm{E}_{\mathrm{T}}\right)$ and the ratio of peritubular $\mathrm{Cl}^{-}$concentration, $[\mathrm{Cl}]_{\mathbf{P}}$, to distal tubular fluid $\mathrm{Cl}^{-}$concentration, $[\mathrm{Cl}]_{\text {T.F. }}$, in normal and salt-depleted rats during $\mathrm{Na}_{2} \mathrm{SO}_{4}$ diuresis. The $[\mathrm{Cl}]_{\text {T.F. fell }}$ to very low levels as fluid passed through the distal tubule. Fifteen per cent of all $[\mathrm{Cl}]_{\text {T.F. }}$ was below a level $(1 \mathrm{mEq}$ per $\mathrm{L})$ that could result from the highest $\mathrm{E}_{\mathbf{T}}(-120 \mathrm{mv})$ if passive reabsorption were solely responsible. Ninety-five per cent of all $[\mathrm{Cl}]_{\text {T.F. }}$ fell below the level that could be produced by the $\mathrm{E}_{\mathrm{T}}$ measured in the same tubule from which the chloride sample was obtained. It is concluded, therefore, that in the distal tubule chloride is actively reabsorbed against electrochemical gradients.

\section{REFERENCES}

1. Windhager, E. E., Whittembury, G., Oken, D. E., Schatzmann, H. J., and Solomon, A. K. Single proximal tubules of the Necturus kidney. III. De- 
pendence of $\mathrm{H}_{2} \mathrm{O}$ movement on $\mathrm{NaCl}$ concentration. Amer. J. Physiol. 1959, 197, 313.

2. Gottschalk, C. W. Micropuncture studies of tubular function in the mammalian kidney. Physiologist 1961, 4, no. 1, 35 .

3. Windhager, E. E., and Giebisch, G. Micropuncture study of renal tubular transfer of sodium chloride in the rat. Amer. J. Physiol. 1961, 200, 581.

4. Pitts, R. F. Some reflections on mechanisms of action of diuretics. Amer. J. Med. 1958, 24, 745.

5. Giebisch, G., and Windhager, E. E. Chloride fluxes across single proximal tubules of Necturus kidney. Fed. Proc. 1959, 18, 52.

6. Windhager, E. E., and Giebisch, G. Measurement of short-circuit current across proximal tubules in the rat kidney. Fed. Proc. 1961, 20, 413.
7. Knisely, M. H. The fused quartz rod technique for transilluminating living internal organ in situ for microscopic study. Anat. Rec. 1954, 120, 265.

8. Alexander, J. T., and Nastuk, W. L. An instrument for the production of microelectrodes used in electrophysiological studies. Rev. sci. Instrum. 1953, 24, 528.

9. Ramsay, J. A., Brown, R. H. J., and Croghan, P. C. Electrometric titration of chloride in small volumes. J. exp. Biol. 1955, 32, 822.

10. Solomon, S. Transtubular potential differences of the rat kidney. J. cell. comp. Physiol. 1957, 49, 351.

11. Gottschalk, C. W., and Mylle, M. Micropuncture study of the mammalian urinary concentrating mechanism: Evidence for the countercurrent hypothesis. Amer. J. Physiol. 1959, 196, 927. 